\title{
Experimental study on the control effect of ground stress on the damage of coal seam mining floor
}

\author{
Gan $\operatorname{Tian}^{1}$, Weiyue $\mathrm{Hu}^{1}$ \\ ${ }^{1} \mathrm{Xi}$ 'an Research Institute of China Coal Technology \& Engineering Group, Xi'an City, Shaanxi Provence, China
}

\begin{abstract}
In order to study on mechanism of in-situ stress control on the coal floor damage during deep coal seam mining, the internal relationship among ground stress, mine pressure and floor water inrush was analyzed base on the increasing distribution rule of ground stress with the increasing depth of stratum. It is shown that the stress on the deep coal seam has obvious control effect on the depth of the floor damage and failure through the experimental study and the statistical analysis of the measured data of the mining damage depth of the coal seam floor. And the calculation formula for the depth of the floor failure in the deep seam mining was put forward.
\end{abstract}

\section{Introduction}

It is imperative to mine deep coal resources along with the upper part coal seam dried up gradually in our country. The dangerousness and destructiveness of water inrush from coal seam floor is more and more serious in mining deep coal seam with the increasing depth of coal seam excavation [1]. This is also intimate relationship with the high in-situ stress environment of deep coal seam roof and floor in addition to the reason of the increasing pressure of aquifer water under the coal seam floor. It is the key technology of safely mining deep coal resources that how to safely and effectively develop the deep coal resources from the condition of high geo-stress and high confined water pressure. We usually focus on water filling source, water filling way and water filling strength about shallow coal seam safely mining under water pressure. We didn't focus too much attention to the control function and control mechanism of the ground stress size on coal seam floor water inrush in the working face, even we ignore them. But the original rock stress of surrounding rock increases rapidly with the increase of buried depth of coal seam. The mechanical properties of surrounding rock, the mechanical response characteristics after coal seam mining and the fracture mechanism of water inrush under high water pressure have different special properties from that of the shallow buried coal seam. The ground stress state becomes the important controlling factors of coal seam floor waterinrush. Therefore, from theory to engineering applications, it is the key scientific and technical problems to systematically study the inherent law of insitu stress size and the buried depth of coal seam, to research the in-situ stress state of surrounding rock, the control mechanism of the high ground stress on mechanical property of coal seam surrounding rock, and damage characteristics of coal seam floor strata under the effect of mining disturbance and water pressure in high ground stress environment and its control effect coal seam floor water inrush, and then obtain the internal relation among the buried depth of coal seam, the size of the ground stress and hazard assessment index. That is the great demand of realizing safety mining deep coal seam under water pressure and in the deep high stress environment.

\section{The relationship between the ground stress and the water inrush of the coal seam floor}

\subsection{Ground stress distribution law}

Ground stress is the primary rock stress in the earth's crust that is not disturbed by mining engineering. It is mainly formed under the joint action of gravitational field and Structural stress field. It is related to various dynamic processes of the earth. The tectonic stress field and the self-weighted stress field are the main components of the geo-stress field. [2] Generally, the Structural stress changes little in the same mining area, so the geo-stress we study here is mainly vertical stress.

In general, the vertical stress is basically equal to the weight of the overlying rock mass. In 1978, E. Brown and E. Hoek [3] based on the data fitting, it is concluded that the vertical stress is proportional to the buried depth of the strata. In recent years, many scholars have conducted a large number of tests and studies on the stress in China.

Figure 1 is the results of stress testing in mining areas such as Lu'an, Yangquan, Huozhou and Fenxi in Shanxi Province [4]. The vertical stress of the strata is mapped with the variation of the depth of the strata. It can be clearly seen from the curve that vertical stress has a good

\footnotetext{
* Corresponding author: Gan Tian: ccritiangan@126.com
} 
linear relationship with the buried depth of the formation, and the vertical stress gradually increases with the buried depth of the formation. The vertical stress is basically equal to the weight of the overlying rock.

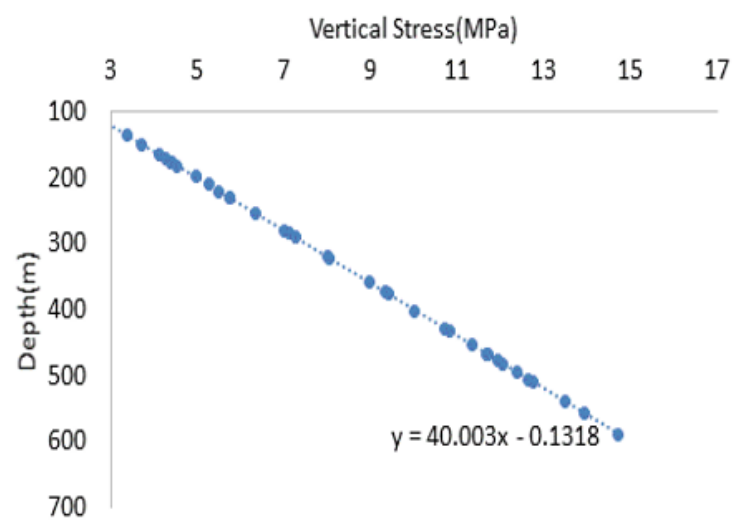

Fig. 1. Relation between vertical stress and buried depth in Shanxi mining area.

\subsection{Relationship between geo-stress and mine pressure}

In the process of coal seam mining, the stress field balance of the original rock in the mining field will be broken and redistributed, and the surrounding rock stress of the corresponding coal seam floor will also change. As a result, displacement, deformation, and even destruction of the floor rock mass will occur. It is called mine pressure that the force generated by underground coal mining activities on surrounding coal masses and related supporting materials such as well lanes, Chambers, and mining face. The supporting pressure is an important part of mine pressure.

The root cause of mine pressure lies in the existence of ground stress, and its essence is the result of superimposed and self-balanced coal seams in the process of mining that caused the stress field of the surrounding rock to be destroyed. The forming expansion zone, compression zone and shear zone of the bottom plate of the remining face lead to the deformation, destruction, collapse, deformation, damage, and other dynamic phenomena of the surrounding rock mass. The disturbance caused by mine pressure will have a direct impact on the development and occurrence of water inrush on the bottom plate. Therefore, it is of great theoretical and practical significance to study and predict the stress distribution and variation of the surrounding rock in the deep coal seam mining field under different stress conditions.

\subsection{Relationship between geo-stress and floor water inrush}

With the increasing of coal seam depth, the effect of ground stress on deep coal seam mining becomes more and more prominent. The greater the depth of the coal seam, the greater the pressure of the bottom rock, the smaller the cracks and pores of the bottom rock mass. Then the permeability of the rock mass will be reduced and its ability to resist high-pressure water will increase. Therefore, under the condition of primary rock stress, the ground stress has a certain inhibitory effect on the original intrusion and development height of coal bed aquifer.

With the increase of the depth of coal seam burial, the vertical stress generated by the overlying strata gradually increases, which causes the mine pressure generated by the mining disturbance in the layer of the floor to increase, and the mineral pressure becomes more obvious. Mining disturbance is more serious to coal seam floor shear and tensile deformation and damage depth of floor disturbance damage is increasing, bottom layer interface high pressure water intrusion damage development height is also increased, resulting in floor water intrusion is possible [5][6][7]. Therefore, the ground stress has a certain induced effect on the floor water inrush in the process of coal seam mining.

\section{Experimental study on the control effect of ground stress on coal seam floor damage}

In general, the surrounding rock stress of the coal seam floor is different under different conditions. The deeper the coal seam is buried, the greater the stress of the bottom floor surrounding rock, and the greater the influence of the ground stress on the deformation and destruction of the bottom plate after coal seam mining, which is of great importance to the study of the mechanism of water intrusion in the bottom floor of deep coal seam mining. In order to study the mechanism of the deformation and destruction of the rock layer isolated from the coal seam floor under different buried stress conditions, the paper studied experimentally the intensity, deformation degree and permeability characteristics of rock blocks under the conditions of different confining pressure and different pore water pressure by rock mechanical test system, and analyzed comprehensively stress field deformation failure and permeability of rock mass mechanism and change laws.

Test plan:

1) The test of saturated limestone block under the conditions of $5 \mathrm{MPa}, 10 \mathrm{MPa}, 20 \mathrm{MPa}$, and $30 \mathrm{MPa}$ under the conditions of $4 \mathrm{MPa}$.

2) Post-peak rock test of limestone rock under $4 \mathrm{MPa}$ condition with the same pore pressure.

Post-peak rock mass specimen is a failure specimen of rock block during the whole process of test. As the specimen has been destroyed, a fracture network has been formed and it has become a fissure permeable medium. Therefore, it can represent the permeability characteristics of the fissure rock mass. During the test, different containment pressure, static pressure, and osmotic pressure are applied to it. The test results reveal the pressure effect and water pressure effect of rock mass strength, deformation and permeability parameters.

During the test, the water pressure applied during the test of strength parameters and deformation parameters is the static water pressure (pore water pressure). The 
water pressure applied during the permeability test is dynamic water pressure (osmotic pressure).

\subsection{Mechanism of surrounding pressure on rock strength}

As the depth of coal seam mining increases, the stress of surrounding rock increases in the mining field. Under the combined action of Highland stress and high water pressure, the strength and deformation characteristics of the rock body in the layer of the coal seam floor of the remining face are different from those of the surrounding rock under the normal stress state of the shallow buried coal floor. Therefore, in the process of coal seam mining, the control effect of different surrounding rock stress on water inrush in coal bed is also different.

Table 1 shows the strength test results of limestone blocks under saturated rock blocks and $4 \mathrm{MPa}$ hydrostatic pressure under different pressure.

Table 1. Table of results of rock strength test.

\begin{tabular}{|c|c|c|c|}
\hline Lithology & $\begin{array}{c}\text { Surrounding } \\
\text { stress/MPa }\end{array}$ & $\begin{array}{c}\text { Peak strength } \\
\text { of saturated } \\
\text { rock blocks } \\
\text { /MPa }\end{array}$ & $\begin{array}{c}\text { Residual strength of } \\
\text { rock mass under 4 } \\
\text { MPa hydraulic } \\
\text { pressure /MPa }\end{array}$ \\
\hline \multirow{4}{*}{ Limestone } & 5 & 120.98 & 16.61 \\
\cline { 2 - 4 } & 10 & 175.00 & 48.21 \\
\cline { 2 - 4 } & 20 & 228.54 & 102.74 \\
\cline { 2 - 4 } & 30 & 283.52 & 153.31 \\
\hline
\end{tabular}

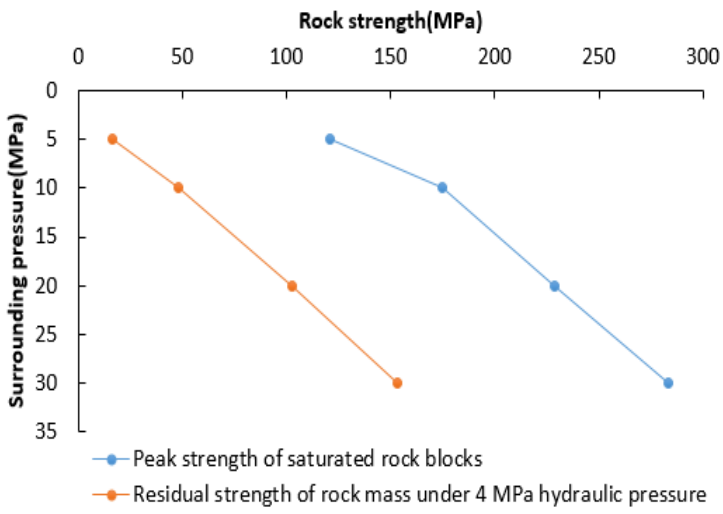

Fig. 2. The elastic modulus change curve of limestone block under different surrounding pressure.

From the data in Table 1 and Figure 2, it can be seen that the strength of the rock mass is significantly affected by the pressure of the surrounding rock, and the strength of the rock mass gradually increases as the pressure increases. The linear relationship between the change of rock strength and the surrounding pressure is proportional.

Table 2 shows the strength test results of saturated rock blocks and $3 \mathrm{MPa}$ hydrostatic pressure under different lithology [8].

From the data in Table 2 and Figure 3, it can also be seen that the change laws of rock strength under different pressures of $4 \mathrm{MPa}, 8 \mathrm{MPa}, 12 \mathrm{MPa}$ and $16 \mathrm{MPa}$ are consistent with different rock blocks of fine sandstone, medium sandstone, crude sandstone and limestone. The saturation strength of fine sandstone under the action of $4 \mathrm{MPa}$ and $16 \mathrm{MPa}$ is $60.33 \mathrm{MPa}$ and 144.33 $\mathrm{MPa}$, respectively. The strength of the surrounding pressure increases by 4 times and the strength of the rock block increases by $84 \mathrm{MPa}$. The strength increases by $139 \%$ from the original. The strength of other rock blocks also increases with the continuous increase of the surrounding pressure. The law of rock strength change is basically directly proportional to the change of surrounding pressure, and rock strength is controlled by the stress of surrounding rock.

Table 2. Table of results of rock strength test.

\begin{tabular}{|c|c|c|c|}
\hline Lithology & $\begin{array}{l}\text { Surrounding } \\
\text { stress/MPa }\end{array}$ & $\begin{array}{c}\text { Peak strength of } \\
\text { saturated rock } \\
\text { blocks } / \mathrm{MPa}\end{array}$ & $\begin{array}{c}\text { Residual strength of } \\
\text { rock mass under } \\
\text { MPa hydraulic } \\
\text { pressure /MPa }\end{array}$ \\
\hline \multirow{4}{*}{$\begin{array}{c}\text { Fine } \\
\text { sandstone }\end{array}$} & 4 & 60.33 & 22.99 \\
\hline & 8 & 96.58 & 44.87 \\
\hline & 12 & 105.20 & 59.33 \\
\hline & 16 & 144.33 & 82.56 \\
\hline \multirow{4}{*}{$\begin{array}{c}\text { Medium } \\
\text { sandstone }\end{array}$} & 4 & 76.05 & 22.47 \\
\hline & 8 & 93.44 & 53.87 \\
\hline & 12 & 126.64 & 68.45 \\
\hline & 16 & 194.65 & 77.95 \\
\hline \multirow{4}{*}{$\begin{array}{c}\text { Crude } \\
\text { sandstone }\end{array}$} & 4 & 59.30 & 20.88 \\
\hline & 8 & 92.37 & 50.27 \\
\hline & 12 & 100.2 & 59.70 \\
\hline & 16 & 130.85 & 71.88 \\
\hline \multirow{4}{*}{ Limestone } & 4 & 74.28 & 21.27 \\
\hline & 8 & 143.39 & 52.15 \\
\hline & 12 & 152.83 & 77.13 \\
\hline & 16 & 180.57 & 99.08 \\
\hline
\end{tabular}

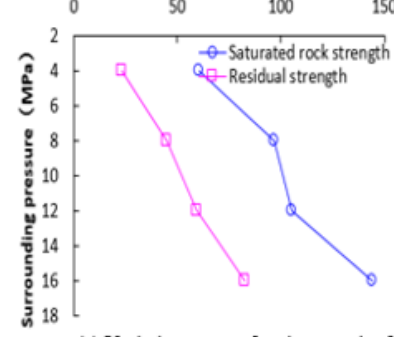

(a) Variation curve of rock strength of fine sandstone block

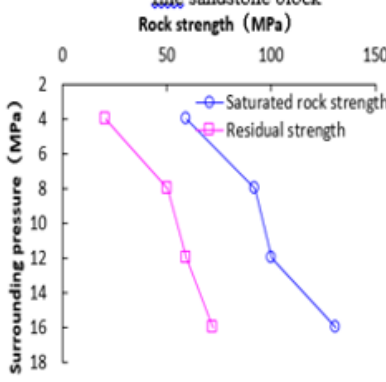

(c) Variation curve of rock strength of soude sandstone block

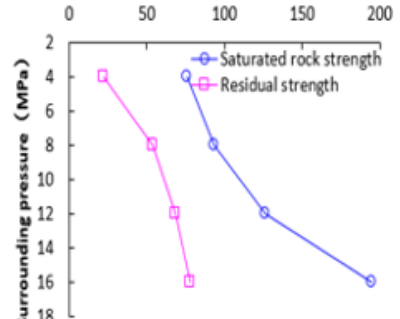

(b) Variation curve of rock strength of middle sandstone block

Rock strength ( $\mathrm{MPa}$ )

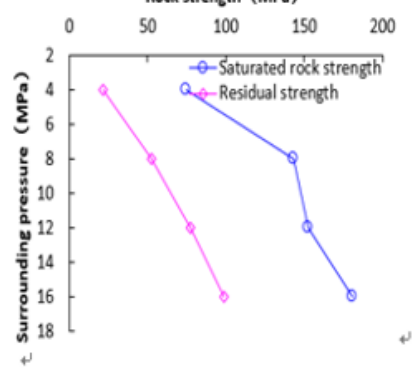

(d) Variation curve of rock strength of limestone block
Fig. 3. The strength change curve of different rock blocks under different confining pressure.

The above strength test results show that, the surrounding rock stress of the coal seam floor will increase with the increase of the depth of coal seam 
burial, the control effect of rock mass strength on the surrounding rock stress will gradually increase, and the ability of rock mass to resist damage will gradually increase. At the same time, it also indicates that the larger the surrounding pressure of the rock mass, the greater the potential energy of its storage, and the greater the severity of deformation and destruction after its destruction. In addition, it was found that the residual strength of the rock was lower as the osmotic pressure increased under the same confining pressure (see Figure 4), and the osmotic pressure was inversely related to the strength of the rock. It shows that the strength of the rock will be reduced and its impedance water capacity will be reduced under the weakening of high-pressure water.

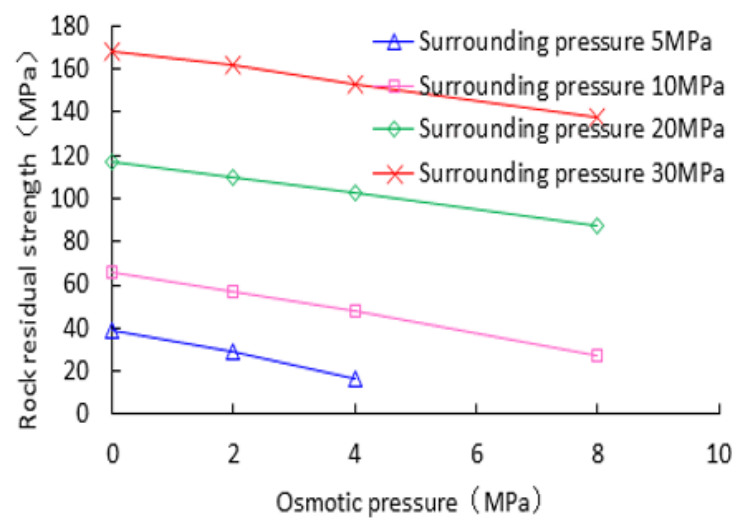

Fig. 4. Variation curve of residual strength of limestone block with osmotic pressure under different confining pressure.

\subsection{Mechanism of surrounding stress on rock mass deformation}

The test method used to study the deformation mechanism of the rock mass is the three-axis compression test method. By analyzing the deformation characteristics of different rock blocks under different confining pressure, the effect of confining pressure on the deformation characteristics of rock masses after peak is studied.

In this paper, elastic modulus (E) and Poisson ratio $(\mu)$ are used to describe the deformation characteristics of different rock blocks under different confining pressures. In the tri-axial compression experiment, we studied the deformation characteristics of the test block by loading the same water pressure and different confining pressure.

According to the three-axis experimental data, we can calculate the two basic deformation parameters of the elastic modulus (E) and Poisson's ratio $(\mu)$ of the rock block. The calculation formula is:

$$
\begin{gathered}
E=\frac{\sigma_{1}-2 \mu \sigma_{3}}{\varepsilon_{1}} \\
B=\frac{\varepsilon_{3}}{\varepsilon_{1}} \\
\mu=\frac{B \sigma_{1}-\sigma_{3}}{\sigma_{3}(2 B-1)-\sigma_{1}}
\end{gathered}
$$

In the formula: $\mathrm{E}$, the elastic modulus of the test rock block; $\mu$, Poisson ratio for rock blocks; $\sigma 1$, axial pressure, $\mathrm{MPa} ; \sigma 3$, surrounding pressure, $\mathrm{MPa} ; \varepsilon 1$, axial strain; $\varepsilon 3$, lateral strain.

Table 2.3 shows the test results of elastic modulus and Poisson ratio of limestone block under saturated state and $4 \mathrm{MPa}$ static water pressure.

Table 3. Results of deformation tests.

\begin{tabular}{|c|c|c|c|c|c|}
\hline \multirow{2}{*}{$\begin{array}{c}\text { Rock } \\
\text { character }\end{array}$} & $\begin{array}{c}\text { Surrounding } \\
\text { pressure/MPa }\end{array}$ & $\begin{array}{c}\text { Deformation } \\
\text { parameters of rock } \\
\text { mass under 0 MPa } \\
\text { hydraulic pressure }\end{array}$ & \multicolumn{2}{c|}{$\begin{array}{c}\text { Deformation } \\
\text { parameters of rock } \\
\text { mass under 4 MPa } \\
\text { hydraulic pressure }\end{array}$} \\
\cline { 2 - 6 } & $\mathrm{E}_{50} / \mathrm{GPa}$ & $\mu$ & $\mathrm{E}_{50} / \mathrm{GPa}$ & $\mu$ \\
\hline \multirow{4}{*}{$\begin{array}{c}\text { Lime- } \\
\text { stone }\end{array}$} & 5 & 65.68 & 0.21 & 7.78 & 0.42 \\
\cline { 2 - 6 } & 10 & 70.39 & 0.26 & 13.24 & 0.34 \\
\cline { 2 - 6 } & 30 & 80.89 & 0.30 & 23.25 & 0.31 \\
\hline
\end{tabular}

As can be seen from tables 3 and figure 5, the elastic modulus of saturated limestone blocks gradually increases under the conditions of $5 \mathrm{MPa}, 10 \mathrm{MPa}, 20$ $\mathrm{MPa}$ and $30 \mathrm{MPa}$ of the surrounding rocks. When the surrounding pressure is $5 \mathrm{MPa}$, the elastic modulus of the rock block is $65.68 \mathrm{GPa}$; When the confining pressure is $30 \mathrm{MPa}$, the elastic modulus of the rock block is $86.07 \mathrm{GPa}$, and the elastic modulus increases by 14.39 $\mathrm{GPa}$. In the same way, the elastic modulus of the rock mass increases under $4 \mathrm{MPa}$ static pressure and different surrounding pressure. There is a linear relationship between the elastic mode and the surrounding pressure of the rock block.

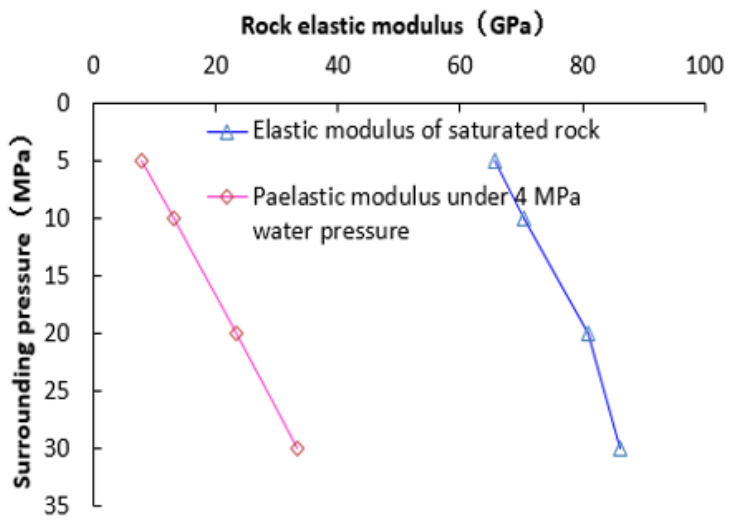

Fig. 5. Variation curve of elastic modulus of limestone under different surrounding pressure.

As can be seen from table 3 and figure 6 , The Poisson ratio of the rock mass initially changed significantly under surrounding pressure of $5 \mathrm{MPa}, 10$ $\mathrm{MPa}, 20 \mathrm{MPa}$, and $30 \mathrm{MPa}$. But the compressive effect of Poisson's ratio decreases or disappears as the maximum Poisson ratio of the surrounding pressure gradually stabilized. Similarly, the Poisson ratio of the rock mass initially changed greatly under the action of 4 $\mathrm{MPa}$ static pressure and different confining pressure, and gradually stabilized with the maximum Poisson ratio of the surrounding pressure. The control effect of Poisson ratio of rock mass decreases or disappears gradually after increasing the confining pressure. The experiment shows that the longitudinal and transverse compressibility of the rock layer gradually decreases and the strength 
gradually increases in the deep coal seam floor under the action of high surrounding pressure.

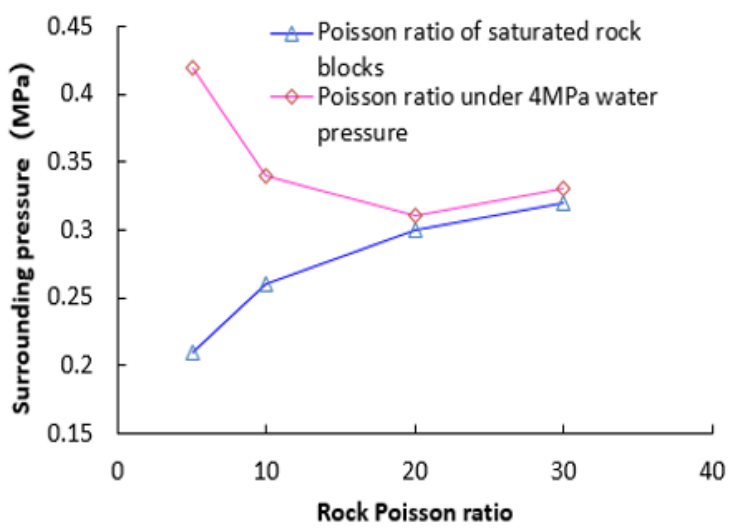

Fig. 6. Poisson ratio variation curve of limestone under different confining pressure.

Table 4 shows the test results of elastic modulus and Poisson ratio of different rock blocks under saturated state and $3 \mathrm{MPa}$ static pressure.

Table 4. Results of deformation tests.

\begin{tabular}{|c|c|c|c|c|c|}
\hline \multirow{2}{*}{$\begin{array}{c}\text { Rock } \\
\text { character }\end{array}$} & \multirow{2}{*}{$\begin{array}{c}\text { Surroundin } \\
\text { g pressure } \\
/ \mathrm{MPa}\end{array}$} & \multicolumn{2}{|c|}{$\begin{array}{l}\text { Rock deformation } \\
\text { parameters under } 0 \\
\text { MPa water pressure }\end{array}$} & \multicolumn{2}{|c|}{$\begin{array}{c}\text { Rock deformation } \\
\text { parameters under } 3 \\
\text { MPa hydraulic } \\
\text { pressure }\end{array}$} \\
\hline & & \begin{tabular}{|c|} 
Elastic \\
modulus \\
$/ \mathrm{GPa}$
\end{tabular} & $\begin{array}{c}\text { Possion } \\
\text { ratio }\end{array}$ & $\begin{array}{c}\text { Elastic } \\
\text { modulus } \\
/ \mathrm{GPa}\end{array}$ & $\begin{array}{c}\text { Possion } \\
\text { ratio }\end{array}$ \\
\hline \multirow{4}{*}{$\begin{array}{c}\text { Fine } \\
\text { sandstone }\end{array}$} & 4 & 14.10 & 0.29 & 6.81 & 0.34 \\
\hline & 8 & 18.60 & 0.29 & 18.98 & 0.37 \\
\hline & 12 & 21.90 & 0.30 & 20.02 & 0.36 \\
\hline & 16 & 20.70 & 0.30 & 19.80 & 0.33 \\
\hline \multirow{4}{*}{$\begin{array}{c}\text { Medium } \\
\text { sandstone }\end{array}$} & 4 & 9.00 & 0.29 & 7.20 & 0.42 \\
\hline & 8 & 13.20 & 0.31 & 16.00 & 0.34 \\
\hline & 12 & 16.90 & 0.32 & 20.60 & 0.33 \\
\hline & 16 & 18.60 & 0.30 & 24.30 & 0.34 \\
\hline \multirow{4}{*}{$\begin{array}{c}\text { Coarse } \\
\text { sandstone }\end{array}$} & 4 & 11.60 & 0.34 & 9.90 & 0.48 \\
\hline & 8 & 15.60 & 0.33 & 20.40 & 0.38 \\
\hline & 12 & 18.10 & 0.32 & 24.90 & 0.35 \\
\hline & 16 & 19.60 & 0.30 & 28.60 & 0.35 \\
\hline \multirow{4}{*}{$\begin{array}{l}\text { Lime- } \\
\text { stone }\end{array}$} & 4 & 29.80 & 0.23 & 10.90 & 0.38 \\
\hline & 8 & 40.00 & 0.25 & 22.90 & 0.31 \\
\hline & 12 & 41.80 & 0.26 & 29.50 & 0.31 \\
\hline & 16 & 41.80 & 0.28 & 34.80 & 0.31 \\
\hline
\end{tabular}

As can be seen from Table 4 and Figure 7 , the elastic modulus of different saturated rock blocks of fine sandstone, medium sandstone, coarse sandstone and limestone increases with the increase of the surrounding pressure under different confining pressures of $4 \mathrm{MPa}$, $8 \mathrm{MPa}, 12 \mathrm{MPa}$ and $16 \mathrm{MPa}$. The elastic modulus is basically linear with the surrounding pressure. Surrounding pressure has a good control effect on the elastic modulus of rock blocks.

Similarly, the elastic modulus increases continuously with the increase of the confining pressure under the action of $3 \mathrm{MPa}$ static water pressure and different confining conditions. The elastic modulus and the confining pressure are basically linear. The surrounding rock also showed a good control effect on the elastic modulus of the rock block
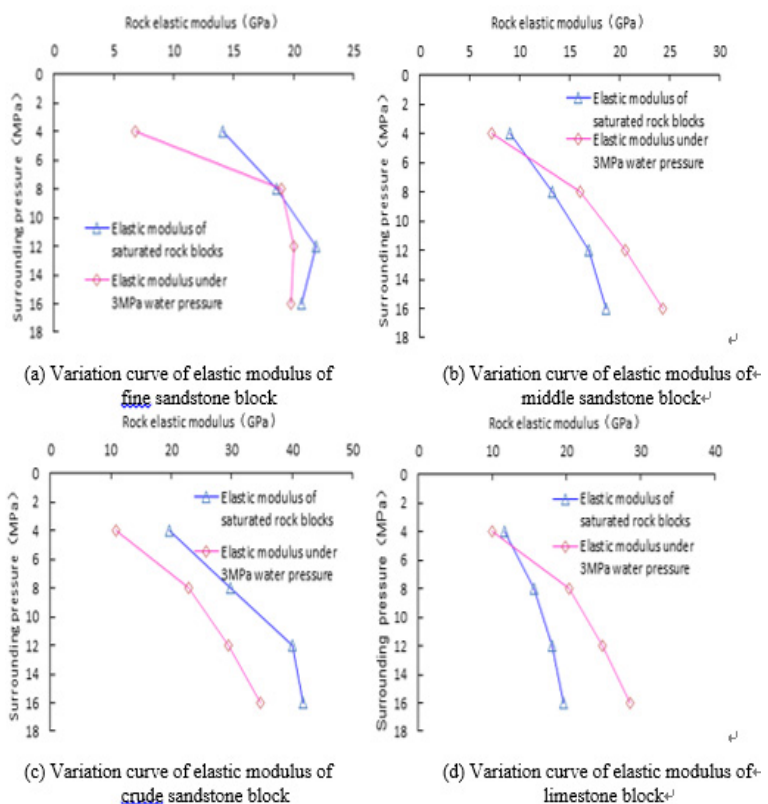

Fig. 7. Variation curve of elastic modulus of different rock blocks under different confining pressure.

Figure 7 shows the relationship between Poisson's ratio and surrounding pressure of fine sandstone, middle sandstone, coarse sandstone and limestone blocks under saturated state and $3 \mathrm{MPa}$ static pressure. It can be seen from the curve that the Poisson ratio of saturated rock blocks increases with the increase of the confining pressure and the initial linear change increases. With the increasing of the surrounding pressure, the change of Poisson's ratio of rock blocks gradually slows down. When the surrounding pressure increases to a certain extent, its influence on the Poisson's ratio of rock blocks gradually decreases, and eventually it basically disappears and tends to a constant. The experimental data show that the water stress and vertical stress of the rock block also increase with the increasing of the surrounding pressure. When the surrounding pressure reaches a certain value, the horizontal and vertical stress of the rock block gradually tends to be equal. The ratio of lateral strain and vertical strain of rock blocks also gradually stabilized, and the compressibility of rock blocks also increased, and the strength of rock blocks also increased. 


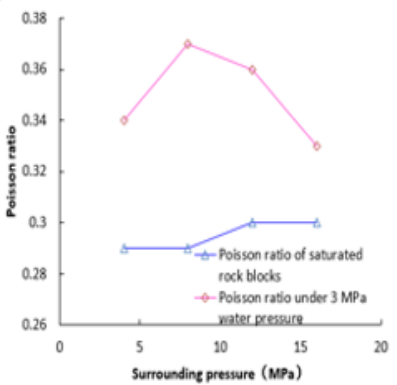

(a) Variation curve of Poisson's ratio of fine sandstone block

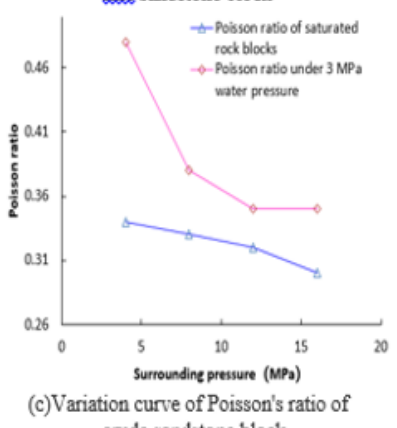

caude sandstone block

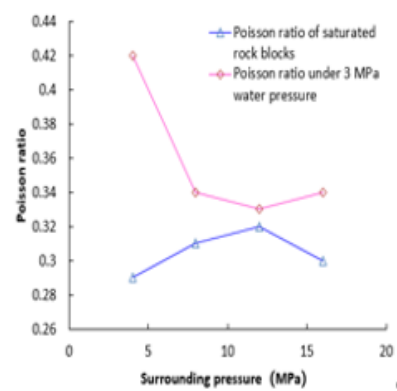

(b) Variation curve of Poisson's ratio of

(b) Variation curve or Poisson's ratio of

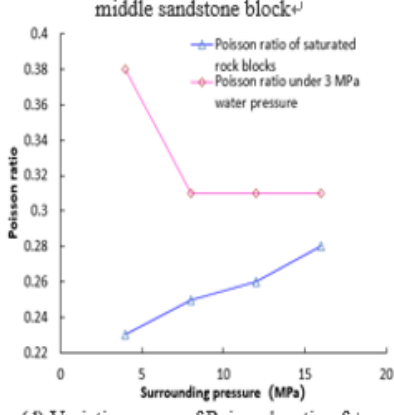

(d) Variation curve of Poisson's ratio of limestone block

Fig. 8. Poisson ratio variation curve of different lithologic blocks under different confining pressure.

According to the comprehensive analysis of the experimental results, the strength of the rock block continues to increase as its surrounding pressure increases, and the corresponding elastic modulus of the rock block increases. This shows that the horizontal stress and vertical stress of the coal bed floor under the stress state of the original rock gradually become equal with the increase of the buried depth. The strength and elastic modulus of the rock formations increase, and their ability to resist deformation and destruction increases. At the same time, the potential energy of the rock mass also increases. However, due to the breaking of the stress field balance of the coal seam floor surrounding the rock, the stress of the bottom plate in the mining area decreases and the expansion and deformation occurs after coal seam mining. The greater the depth of coal seam burial, the greater the deformation of the coal seam floor after the stress is released. At the same time, the damage depth of the coal seam floor is greater after coal seam mining. This shows that the ground stress has obvious control effect on the mining deformation of the coal bed.

In addition, it can be seen from Figure 6 to 8 that there is a significant difference in the strength parameters of saturated rock blocks and rock blocks under water pressure, and the elastic modulus of saturated rock blocks is greater than the elastic modulus of rock blocks under water pressure. The Poisson ratio of saturated rock block is smaller than the Poisson ratio of rock block under water pressure. The test shows that, in the process of deep coal seam mining under high water pressure, the strength of the rock formation in the pilot zone will be reduced due to the splitting of the water in the high-pressure aquifer under the coal seam floor caused by the disturbance of coal seam recovery. The impedance of the rock formation in the conduction zone also weakened or even disappeared.

\subsection{Statistical analysis of measured data of floor damage depth}

In order to further study the relationship between the damage depth of coal seam floor and the ground stress and surrounding stress, the measured data of the damage depth of coal seam floor in 67 coal mines in China are calculated. And the distribution map of the relationship between the depth of rock damage and the depth of coal seam burial was drawn (Figure 9).

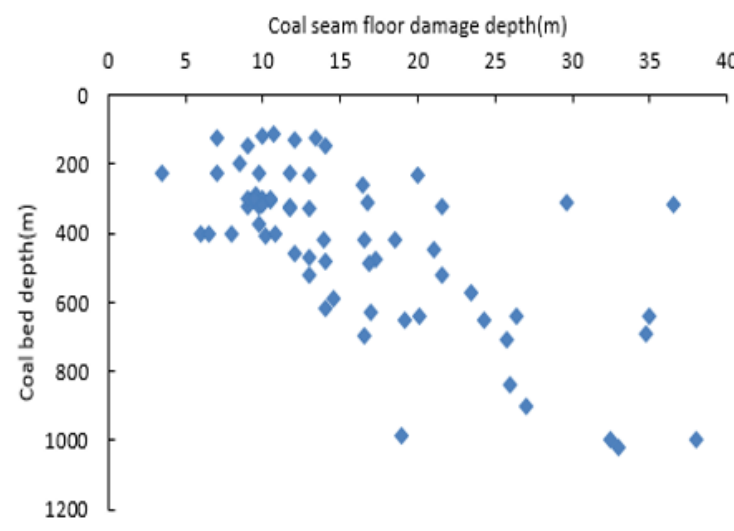

Fig. 9. The curve of damage depth change with buried depth of bottom plate measured in some coal mines in China.

It can be seen from Figure 10 that the general trend of the damage depth of coal seam floor is increasing with the increase of the depth of coal seam. In addition, from the data distribution in the figure, when the depth of coal seam is less than about $400 \mathrm{~m}$, the data distribution of the destruction depth of the floor rock layer is relatively chaotic, the law is not obvious, and the data on the destruction depth are relatively concentrated, and the basic distribution is relatively concentrated at about $10 \mathrm{~m}$. This shows that the damage depth of the bottom layer is not obviously controlled by the stress when the depth of coal seam mining is less than $400 \mathrm{~m}$.

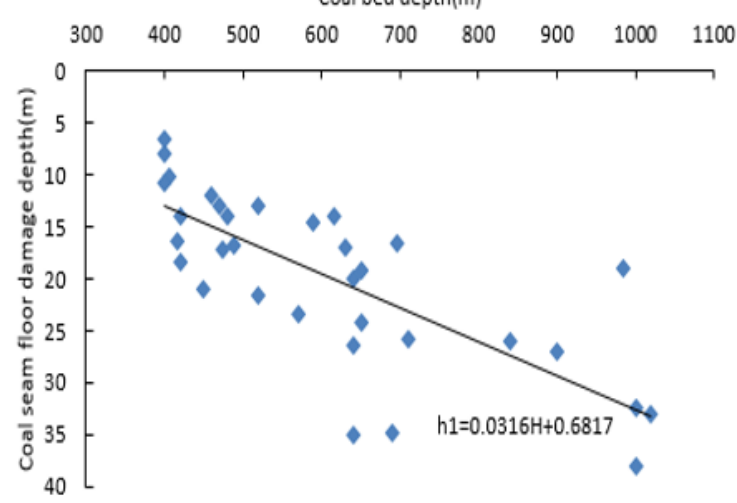

Fig. 10. The relationship between rock damage depth and buried depth of coal seam buried greater than $400 \mathrm{~m}$ floor.

Figure 10 shows the distribution of the relationship between the damage depth of the floor rock layer and the depth of the coal seam after coal seam mining when the buried depth is greater than $400 \mathrm{~m}$. It can be seen from the figure that when the depth of coal seam is 400 to $1000 \mathrm{~m}$, as the depth of coal seam is continuously increased, the damage depth of the coal floor is also increased, and the damage depth of the floor rock layer is basically linear with the buried depth. This shows that 
when the depth of coal seam is greater than $400 \mathrm{~m}$, the damage depth of rock floor of coal seam mining is controlled by the stress.

By fitting the measured data, we can obtain the formula for calculating the rock damage depth of deep coal seam mining floor when the depth of coal seam is greater than $400 \mathrm{~m}$ :

$$
h_{1}=0.0316 H+0.6817
$$

The formula for calculating the damage depth of the bottom layer only considers the influence of the depth of coal seam on the damage depth of the bottom layer, but does not consider the influence of the slope length, height and coal seam inclination of the back mining face on the damage depth of the bottom layer. Therefore, the formula is not perfect enough. However, it has certain guiding significance for coal seam mining in the same mining area.

According to the numerical simulation results and the measured statistical data, it can be seen that the disturbance and destruction depth of the watertight rock layer in the coal seam floor of the remining face increases with the increase of the depth of the coal seam and the vertical ground stress. The disturbance failure depth is proportional to the burial depth and surrounding stress of the floor layer. The theoretical analysis results are consistent with the measured results.

\section{MAIN CONCLUSIONS}

The following main conclusions are drawn:

1) Ground stress (vertical stress) increases with the deepening of coal seam mining depth, which is proportional to the depth of coal seam burial.

2) Mine pressure is the result of superposition and self-balancing due to the destruction of the stress field of the surrounding rocks in the mining process, and the greater the buried depth, the greater the mine pressure generated by the recovery of the coal seam. The damage depth of disturbance on coal bed floor is also increasing, and the ground stress in coal seam excavation has a certain induced effect on the water inrush of coal floor.

3) Through the strength test of rock samples under different conditions, the change laws and mechanism of rock strength and rock mass deformation under different conditions are analyzed and studied. It is concluded that with the increase of rock compaction its strength increases gradually and its resistance to deformation increases. Tests show that the depth of rock excavation disturbance and destruction in the bottom floor of the coal seam increases with the increase of the surrounding rock stress, and the stress of surrounding rock has obvious controlling effect on the plastic deformation and failure of coal bed. The greater the vertical stress on the top plate of the coal seam remining face, the greater the stress of the surrounding rock on the coal seam floor. Correspondingly, the risk of floor water inrush in the process of coal seam recovery is also greater.

4) According to statistical data analysis, under the same mining technology, the overall trend of rock damage depth in the coal bed floor is to increase with the increase of coal seam depth, and the damage depth of the ground floor rock layer is basically linear. The damage depth of rock floor in coal seam mining is controlled by the stress.

\section{Acknowledgment}

China Coal Engineering Group Xi'an Institute Fund Project (2015XAYMS16)

\section{REFERENCES}

1. Jincai Zhang, Yuzhuo Zhang, Tianquan Liu. Rock mass seepage and coal seam floor water penetration. Beijing: Geological Publishing House. 1997.

2. Ning Zhang. yanti initial stress field development law study, Master's thesis, Zhejiang University. 2002.

3. BROWN E T, HOEK E. Technical note trends in relationships between measured in-situ stress and depth. Int. J. Rock Mech. Min.Sci. and Geomech. Abstr. 15(4): 211-215, (1978)

4. Hongpu Kang, Jian Lin, etc.. Study on distribution characteristics of underground stress field in Shanxi coal mine area. Journal of Geophysics, 52(7): 17821792, (2009)

5. Weiyue $\mathrm{Hu}$, Shangxian Yin. Excavation disturbance dynamics mechanism of water inrush disaster on coal face. Journal of Rock Mechanics and Engineering, 29(increase 1): 3344-3349, (2010)

6. Weiyue Hu, Gan Tian, Kangkang Li. Mechanism of Impedance and High Pressure Water Intrusion in Coal Sealing Floor. Coalfield Geology and Exploration, 36(6): 38 -- 41, (2008)

7. HUWY. Standard on water new company and water made company company sources. Products of the 13th International Association on Area Research. 2004.

8. Zaibing Liu. Study on the percolation-stress coupling effect of rock mass and the water-inrush effect of coal seam floor. General Institute of Coal Science. 2014.

9. Gan Tian. Study on stress control mechanism of water inrush in bottom floor of deep coal seam mining. General Institute of Coal Science. 2015. 